\title{
Canarias Libre: los orígenes del nacionalismo canario en el interior de las islas (1960-1965) ${ }^{1}$
}

\author{
Néstor GARCÍA-LÁZARO² y Zebensui López TrujILlo \\ Universidad de Las Palmas de Gran Canaria; Universidad de La Laguna \\ nestorgarcia1984@yahoo.es
}

Recibido: 01/06/2012

Aceptado: 10/06/2013

\section{RESUMEN}

El presente artículo se ocupa de analizar la trayectoria del Movimiento Canarias Libre, primera organización nacionalista surgida en el interior del Archipiélago Canario, que tuvo un papel destacado en el resurgimiento tanto del nacionalismo canario como de la oposición al franquismo en las Islas. Para ello, se emplea documentación inédita que ha permitido profundizar en el ideario y praxis política de esta incipiente organización, que se había abordado hasta este momento a través del uso exclusivo de las fuentes orales. Al mismo tiempo, se calibra el impacto social y político que tuvo, así como su acceso a la agenda del gobierno del régimen franquista.

Palabras clave: nacionalismo, franquismo, descolonización, movimientos sociales, propaganda.

\section{Canarias Libre: the Origins of Canary Nationalism Inside the Islands (1960 - 1965)}

\begin{abstract}
This paper deals with the Movimiento Canarias Libre, the first nationalist organization in the Canary Islands, which had a important role in both the resurgence of Canarian nationalism and the opposition to Franco within the archipelago. Through the use of unpublished documents we have been able to analyze in depth the ideology and praxis of that organization, which up to now had been studied only through oral sources. At the same time, we try to measure its social and political impact, as well as its influence in the agenda of the successive Francoist governments.
\end{abstract}

Key words: Nationalism, Francoism, Decolonization, Social Movements, Propaganda.

Referencia normalizada: García-Lázaro, N.; López Trujillo, Z. (2013). “Canarias Libre: los orígenes del nacionalismo canario en el interior de las islas (1960-1965)". Cuadernos de Historia Contemporánea, 35, 219-242.

Sumario: Introducción. 1. Ahora somos canarios 2. Tagoror de Gran Canaria. 3. Hombre Canario 4. Viva Canarias Libre 5. Desarticulación 6. Conclusiones 7. Referencias bibliográficas.

1 Archivo General de la Administración (AGA), Archivo Histórico del Partido Comunista de España (AHPCE), Archivo Histórico Provincial de Las Palmas (AHPLP), Archivo Histórico de la Transición Democrática en Canarias (AHTDC), Canarias Libre o Movimiento Canarias Libre (CL), Partido Comunista de España (PCE), Partido Nacionalista de Canarias (PNC), The National Archives (TNA).

2 El autor ha realizado este trabajo en el marco del proyecto "Recuperación de la memoria histórica de la represión franquista en Canarias: fuentes escritas y orales", financiado por el Ministerio de la Presidencia en el marco de las subvenciones destinadas a actividades relacionadas con las víctimas de la guerra civil y del franquismo correspondientes al año 2011, número de proyecto 95.1. 


\section{Introducción}

Durante la década de 1960 se produce en España el resurgimiento de la cuestión nacional y territorial, que es considerada por algunos historiadores como uno de los factores que impulsó la oposición antifranquista, así como también tuvo un papel relevante en la crisis final de legitimación de la dictadura de Franco. En este proceso, según Xosé M. Núñez Seixas, confluyen varias dinámicas, como es la continuidad de los movimientos nacionalistas de anteguerra por un lado, y el surgimiento de nuevos nacionalismos y la reformulación en clave izquierdista y anticolonial de los mismos, por el otro. Por lo que en los sesenta confluyen en el Estado español nuevos y viejos nacionalismos ${ }^{3}$.

Podemos considerar al nacionalismo canario como parte integrante de los nuevos nacionalismos que surgen en la década de 1960 en España, aunque es a mediados del siglo XX cuando comienzan a aparecer en Canarias los primeros síntomas de la recuperación del nacionalismo insular que había nacido a finales del siglo XIX entre los emigrantes canarios en América. Éste fue un período relativamente corto, con escasa influencia en el interior de las Islas y que se concluyó con la muerte en 1912 del máximo referente del movimiento y con el manifiesto de tregua de 1898, con el que el PNC abandonaba toda actividad contra España ante lo que parecía una inminente invasión inglesa de las Islas. En cambio, el nuevo nacionalismo canario que comenzaba a dejarse sentir a mediados de los años 50, iba a iniciar un proceso mucho más amplio a lo largo de todo el siglo XX, hasta convertirse en un elemento indisociable de la realidad social, política y cultural del Archipiélago Canario.

Con este trabajo, lo que pretendemos es hacer un recorrido por los orígenes del nacionalismo canario de segunda ola a través del Movimiento Canarias Libre, surgido en la isla de Gran Canaria en 1961 y desarticulado apenas un año después. A pesar de esa corta existencia, CL tuvo la importancia de ser la primera organización nacionalista canaria cuya sede y actividad principal se encontraba en el interior del Archipiélago, a diferencia del nacionalismo precedente. Sin olvidar el papel destacado que tuvo en la reconstrucción del movimiento obrero y nacionalista y de la oposición al franquismo en la isla, engrosando las filas del Partido Comunista de España una vez desmantelada la organización e introduciendo en su seno el debate y la reflexión sobre la cuestión nacional.

El fenómeno nacionalista canario se ha abordado de manera parcial desde que en los años 80 la propia influencia del nacionalismo y los cambios producidos en el seno de la historiografia, motivaran la aparición de diversos trabajos que han intentado, con fortuna dispar, ir analizando partes concretas del proceso sin ofrecer una explicación que tuviera el grado suficiente de profundidad que la complejidad del fenómeno requiere. En líneas generales, los investigadores se han centrado fundamentalmente en las ramificaciones ideológicas y estratégicas y en las fórmulas orgánicas resultantes ${ }^{4}$.

3 NÚÑEZ SEIXAS, Xosé M.: "Nuevos y viejos nacionalistas: la cuestión territorial en el tardofranquismo, 1959-1975", Ayer, 68 (2007), pp. 59-87.

4 LÓPEZ TRUJILLO, Zebensui: "Historiografía y nacionalismo en Canarias: una primera aproximación”, en Roberto GONZÁLEZ (coord.): Actas de las III Jornadas Prebendado Pacheco de Investigación Histórica, Santa Cruz de Tenerife, Ayto. de Tegueste, 2011, pp. 355-374. 
Asimismo, los estudios sobre la oposición al franquismo en Canarias son escasos, reduciéndose a algunas aportaciones interesantes sobre la reorganización del PCE y sobre uno de los factores que mayores debates generó entre las filas de los comunistas isleños: la cuestión nacional. De ellos, destaca el trabajo desarrollado por Agustín Millares Cantero y Pilar Domínguez Prats ${ }^{5}$.

Al margen de estas referencias, el único intento por abordar el caso de CL de una manera más amplia se lo debemos al historiador Domingo Garí Hayek, quien en 1990 publicó una monografía en la que analizaba, utilizando la oralidad como fuente principal, la aparición, desarrollo y desaparición de CL, en conexión con su contexto social, económico, político e internacional ${ }^{6}$. El recurso a las fuentes orales realizado por Garí Hayek era la única opción metodológica posible en aquél momento, ya que la documentación conocida y accesible no permitía desentrañar la mayor parte de los componentes del movimiento y de su actividad. Tanto la prensa como las fuentes internas del régimen evitaban en lo posible airear la conflictividad social o la disidencia política, por lo que rastrear, como veremos, información útil a través de estas vías será extremadamente complicado. A esta situación había que sumar la inexistencia de un archivo interno del grupo, que habría permitido no solo el acceso directo a las primeras reflexiones del nacionalismo canario de segunda ola y a sus principales presupuestos, sino que también hubiera facilitado el análisis crítico de los testimonios orales de los activistas, recogidos treinta años después. En cambio, la mayor parte de los protagonistas del movimiento seguían vivos en el momento de iniciar su estudio, de ahí el protagonismo que el recurso a las fuentes orales tuvo en este trabajo ${ }^{7}$.

La situación documental ha cambiado recientemente, gracias a la consulta y acceso a nuevos materiales escritos procedentes de distintos archivos y fondos documentales, que han posibilitado, en algunos casos, examinar y analizar el alcance de toda esta valiosa información oral, mucha de ella irrecuperable por el fallecimiento de algunos de los protagonistas; y en otros, ampliar el conocimiento que sobre determinados temas se tenía. En este sentido, debemos destacar la importancia de algunos textos inéditos que han permitido conocer aspectos ideológicos y programáticos con un alcance desconocido hasta el momento. Estos se basan en dos grupos: el primero de ellos lo constituye la documentación generada o enviada al Gobernador Civil de Las Palmas, que en la actualidad se encuentra tanto en el AHPLP como en el AGA; mientras que el segundo lo forman una serie de cartas redactadas por los miembros del Canarias Libre que se encuentran en el AHPCE, debido a los lazos que CL tenía con el PCE, así como por la posterior militancia de sus integrantes en este Partido. Por otro lado, nuestra investigación también se ha enriquecido de las memorias publicadas por algunas de las personas que pertenecieron a este movimiento nacionalista, así como de las entrevistas que les realizaron algunos historiadores durante la década de los ochenta y los noventa del siglo

5 MILlARES CANTERO, Agustín, DOMÍNGUEZ PRATS, Pilar: "La cuestión nacional entre los comunistas grancanarios (1959-1971)" en Manuel BUENO, Carmen GARCÍA y José HINOJOSA (coords.): Historia del PCE. I Congreso, 1920-1977, Madrid, Fundación de Investigaciones Marxistas, 2007, vol. II, pp. $153-165$.

6 GARÍ HAYEK, Domingo: Historia del Movimiento Canarias Libre: 1960-1962, Las Palmas de Gran Canaria, Benchomo, 1990.

7 Idem. 
pasado. Ésta ha sido la única forma que hemos tenido de acceder a la historia oral ${ }^{8}$, debido a que muchos de los hombres que formaban parte de CL han muerto, se encuentran en un delicado estado de salud, o no han querido ser entrevistados. Por este motivo no hemos podido diseñar nuestro propio proyecto de historia oral sobre Canarias Libre, lo que nos hubiera permitido contrastar su percepción o capacidad de influencia en la movilización, sus objetivos y sus limitaciones, entre otros aspectos.

Ante estas nuevas circunstancias, el objetivo de este artículo es realizar un primer intento por sintetizar, en definitiva, el conocimiento que tenemos sobre CL como génesis del resurgimiento nacionalista canario, y al mismo tiempo, ofrecer algunos nuevos análisis a la luz de las recientes expectativas que abre el manejo de nueva documentación escrita, poniendo, asimismo, un especial interés en la práctica social de dicho movimiento, sumándonos a las investigaciones que sobre historia social del antifranquismo se están desarrollando en estos últimos años ${ }^{9}$.

\section{Ahora somos canarios}

A partir de los primeros años de la década de 1950, en la Universidad de La Laguna comenzó a crecer el descontento entre el estudiantado, causado, por una parte, por un clima de creciente tensión en otras universidades del Estado y, por otra, por la reivindicación de algunos asuntos concretos como, por ejemplo, la subida de los precios de los transportes marítimos y urbanos, que originó los mayores conflictos de este período. Se estaba asistiendo a las primeras expresiones del resurgimiento de la actividad opositora al franquismo en las Islas, iniciado por los estudiantes universitarios y extendido, posteriormente, a otros sectores ${ }^{10}$.

Es en este contexto en el que se observa la presencia de los primeros atisbos nacionalistas entre el estudiantado insular, como se percibe en la nota informativa emitida por la Dirección General de Seguridad, a tenor de una manifestación estudiantil celebrada en 1954 contra la subida de la tarifa del billete del transporte marítimo:

se empieza [en Tenerife] a hablar en corrillos y tertulias de la independencia de Canarias. Igualmente circuló el rumor de que los manifestantes de Las Palmas de Gran Canaria, portaron una pancarta en los siguientes términos: Antes de la guerra y en la guerra fuimos españoles, ahora somos canarios ${ }^{11}$.

8 Aunque en el presente artículo empleamos algunas entrevistas realizadas por Néstor García Lázaro en el marco de su proyecto de Tesis Doctoral sobre la propaganda ilegal en Canarias. Éstas fueron realizadas en 2010 a Arturo Cantero, un miembro de la organización, y a Sergio Hernández Ibrahim, un joven que acudió al partido de fútbol del Estadio Insular.

9 MOLINERO, Carme: "Una gran apuesta: la oposición política a través de la movilización social", en Manuel Bueno Lluch, Sergio Gálvez Biesca (eds.): Nosotros los comunistas. Memoria, identidad e historia social, Fundación de Investigaciones Marxistas / Atrapasueños, Sevilla, 2009, p. 255.

10 CABRERA ACOSTA, Miguel Ángel; LÓPEZ TRUJILlO, Zebensui: "Antonio Cubillo: de la oposición al franquismo al nacionalismo africanista canario", en Xosé Manuel NÚÑEZ SEIXAS; Fernado MOLINA APARICIO (eds.): Heterodoxos de la Patria: biografías de nacionalistas atipicos de la España del siglo XX, Granada, Comares, 2011, pp. 222-223.

11 AHTDC, Dirección General de Seguridad, Nota informativa, Tenerife, 22 de marzo de 1954. Véase también, CABRERA ACOSTA, M. Á.; LÓPEZ TRUJILLO, Z.: “Antonio Cubillo...”, pp. 223-224. 
El propio Antonio Cubillo Ferreira, principal ideólogo de la segunda etapa del nacionalismo canario y protagonista directo de estos acontecimientos, apunta a su etapa universitaria como el momento en el que toma el primer contacto con estas ideas, aunque, como él mismo reconoce, de una manera muy primaria:

aunque ya en los años de la Universidad nos habíamos planteado el problema de la nación, estábamos inmaduros y no habíamos podido establecer entre nosotros mismos el concepto de nación ${ }^{12}$.

Para identificar con claridad la presencia de algunos componentes nacionalistas en las Islas, deberemos esperar a bien entrada la segunda mitad de los años 50.

En cuanto a Las Palmas de Gran Canaria, a comienzos de la década de 1950 se creaba la Iglesia Cubana, una agrupación informal de estudiantes que provenían de los restos de una tradición liberal que había sobrevivido a la Guerra Civil. Estos jóvenes formaron una especie de cenáculo intelectual en el que intercambiaban lecturas sobre las que posteriormente discutían, teniendo un gran interés por la música clásica, la filosofía y la literatura. Las actividades intelectuales eran combinadas con acciones provocadoras y satíricas de corte fundamentalmente anticlerical. El grupo estaba formado por jóvenes de clases medias que en un primer momento no se encontraban politizados, pero ante la entrada de nuevos miembros a finales de la década hizo que se llegase a hablar de una "Iglesia Roja". Posteriormente, muchos de los integrantes de la Iglesia Cubana, serían parte del núcleo dirigente del CL ${ }^{13}$.

Por otra parte, la primera gran característica de esta nueva generación de opositores es que no vivió en primera persona la Guerra Civil ni la represión posterior. Lo que hace que carezcan de la experiencia de la clandestinidad y de las formas de lucha anteriores, además de patrones mentales e ideológicos del período de la Guerra y la Postguerra, lo que generará unas expectativas de cambio y una praxis política sustancialmente diferentes a la anterior generación de opositores ${ }^{14}$.

La conexión con grupos opositores de ámbito estatal se había roto en gran medida y ciertos elementos ideológicos que imprimían cohesión solo eran visibles fundamentalmente entre los líderes de los sobrevivientes núcleos comunistas. Grupos que, por otra parte, habían sido duramente reprimidos en la operación represiva de la segunda mitad de los años 40. En consecuencia, la década de 1950 se caracterizó por la desarticulación organizativa de las fuerzas de oposición al franquismo en las Islas. Debido al acoso policial, que realizó continuas oleadas de detenciones entre 1946 y 1951, el Comité Regional del PCE decidió autodisolverse, siendo escasos los militantes que mantuvieron el contacto, rehusando cualquier actividad política. Por

12 CUBILlo FERREIRA, Antonio: Trópico gris. Semimemorias-2, Santa Cruz de Tenerife, CCPC, 2005 , p. 17. Véase también, CABRERA ACOSTA, M. Ả.; LÓPEZ TRUJILLO, Z.: “Antonio Cubillo...”, p. 223.

13 MILLARES CANTERO, Agustín: "En busca de la iglesia cubana", en Arturo CANTERO SARMIENTO: Las Palmas 1950: vida, hechos y milagros de la famosa "Iglesia cubana", Las Palmas de Gran Canaria, Ediciones del Cabildo Insular de Gran Canaria, 1993, pp. 7-24.

14 LÓPEZ TRUJILLO, Zebensui: Imaginar la nación canaria: el papel de Antonio Cubillo en el resurgimiento de los movimientos obrero y nacionalista (1956-1978), 2010, p. 62. Trabajo de investigación inédito. Diplomatura en Estudios Avanzados y Suficiencia Investigadora (DEA). Departamento de Historia. Universidad de La Laguna. 
otro lado, los "viejos" socialistas, aunque conservaban vínculos con la dirección, su actividad se circunscribió en la práctica a una serie de reuniones organizadas por el socialista Felo Monzón en la Escuela de Arte Luján Pérez, de la que era director ${ }^{15}$. Es en este contexto de práctica inexistencia de estructuras organizativas en los dos partidos políticos que habían sobrevivido al Golpe de Estado, en el que surge y se organiza CL sin una conexión clara con el cuerpo opositor anterior ${ }^{16}$.

De tal manera que la influencia de esta vieja oposición fue limitada, solo incorporándose más tarde cuando ya la nueva oposición política y la actividad sindical se encontraban en funcionamiento. En cualquier caso, dicha oposición encarna una perspectiva diferente de lo qué es y de cómo debe enfrentarse el franquismo, cuestión que, por otra parte, será el principal elemento de discordia entre ambos grupos a la hora de desarrollar una actividad opositora conjunta ${ }^{17}$.

En cuanto al detonante principal de la conformación del grupo, todos los autores, así como la mayoría de protagonistas, coinciden en afirmar que la ejecución por parte del régimen franquista del grancanario Juan García Suárez (El Corredera) en 1959, actuó como motor principal para la concreción de todas aquellas ideas que se venían fraguando en una organización política clandestina y en el comienzo de su actividad.

Juan García fue un vecino del municipio de Telde, que tomó parte activa en la resistencia republicana en su ciudad natal durante los días 18 y 19 de julio de 1936. Debido al triunfo de la sublevación militar en Canarias decide huir a los montes de la isla de Gran Canaria desde ese mismo verano ${ }^{18}$. Según afirman su abogado defensor, testimonios orales de militantes antifranquistas y las investigaciones de algunos historiadores, El Corredera, estuvo escondido durante más de dos décadas por distintos puntos de la geografía insular, y contaba con el apoyo popular que le brindaba víveres y alojamiento ${ }^{19}$.

El motivo de su detención en 1958 y la posterior realización de un juicio civil y militar en 1959 fue la acusación que pesaba sobre él de haber matado a finales de la década de 1940 a un falangista de su ciudad que amedrentaba a su familia. Como ha demostrado Alfonso Calzada Fiol, este suceso estuvo lleno de irregularidades desde el comienzo, con declaraciones tomadas bajo tortura a los posibles testigos y $\sin$ pruebas fidedignas que incriminaran a Juan García ${ }^{20}$. Por este motivo, su figura le-

15 ALCARAZ ABELLÁN, José: La resistencia antifranquista en las Canarias Orientales (1939-1960), Las Palmas de Gran Canaria, El Museo Canario, Caja Insular de Ahorros de Canarias, 1991, pp. 101-108, 115119; GARÍ HAYEK, Domingo: Historia del Movimiento Canarias Libre..., p. 133.

16 MILLARES CANTERO, Agustín; DOMÍNGUEZ PRATS, Pilar, "La 'cuestión nacional' entre los comunistas grancanarios...”, pp. 154-156.

17 LÓPEZ TRUJILLO, Zebensui: Imaginar ..., pp. 62-63.

18 ALCARAZ ABELLÁN, José: La resistencia antifranquista..., p. 127.

19 El relato del abogado en CALZADA FIOL, Alfonso: La verdad sobre "el Corredera", Las Palmas de Gran Canaria, Inforcasa, 1989; mientras que los testimonios de los militantes, así como las investigaciones de los historiadores pueden leerse en ALCARAZ ABELLÁN, José: La resistencia antifranquista..., pp. 126-134; GARÍ HAYEK, Domingo: Historia del Movimiento Canarias Libre..., pp. 87-91; MILLARES CANTERO, Sergio: Fernando Sagaseta, la vida de un luchar irremediable, Las Palmas de Gran Canaria, Centro de la Cultura Popular Canaria, 1994, pp.101-116.

20 Para un relato detallado de los acontecimientos remitimos al libro escrito por Alfonso Calzada Fiol, en el que describe cada una de las anomalías que se sucedieron. CALZADA FIOL, Alfonso: La verdad sobre "el Corredera... 
vantó afectos y muestras de solidaridad entre amplios sectores de la población. Una muestra de ello fue la gran cantidad de personas que acudieron a presenciar la entrada del reo a la Audiencia Provincial el día en el que se celebraba el juicio civil. Según le escribía el Capitán-Jefe de la circunscripción de Las Palmas de la Policía Armada y de Tráfico al Gobernador Civil de Las Palmas, "debido a la aglomeración del público" se "impedía el paso del procesado, así como la entrada a la Sala", por lo que "fue necesario sacar las defensas al objeto de restablecer el orden". En este documento se recoge por parte de los policías que en el lugar existía "un pequeño grupo compuesto en su mayoría por chiquillería [que] hicieron unos aplausos a la entrada y salida de la Audiencia del referido forajido" 21 .

De tal manera, que con su muerte se avivaron una serie de sentimientos que conmocionaron a esa nueva generación de opositores políticos, generando un proceso de radicalización y de paso a la acción inmediata ${ }^{22}$. Además, el caso de El Corredera fue percibido como una auténtica injerencia externa en las Islas y una agresión directa del régimen imperante en España contra los canarios, lo que es una lectura en cierta medida lógica si tenemos en cuenta el contexto social en el que se produce ${ }^{23}$. Según Sagaseta,

todo esto [el asesinato de El Corredera], efectivamente, ayudó también en la toma de conciencia de los canarios sobre la necesidad de separación, o por lo menos de la autonomía; de que la ciudadanía no dependiera de que unos señores en Madrid tocaran el pito y bailáramos todos ${ }^{24}$.

Fruto de la situación generada tras la muerte de Juan García mediante el procedimiento del garrote vil algunas personas, que posteriormente formaron parte de CL, empezaron a realizar unas charlas críticas en las que se debatía sobre la situación política y económica de Canarias en el contexto de la dictadura franquista. Éstas derivaron posteriormente en una serie de reuniones políticas ${ }^{25}$, en las que además se hacían elaborados análisis de la situación insular ${ }^{26}$.

21 AHPLP, Gobierno Civil, Legajo 7/6/1. Guardia Civil, Policía Armada. Partes y servicios. Año 1959. Escrito núm. 120 del Capitán-Jefe de la Circunscripción de Las Palmas de la Policía Armada y de Tráfico enviado al Gobernador Civil de Las Palmas, 30 de enero de 1959. Aunque no podemos afirmarlo con total seguridad, pensamos que entre esa "chiquillería" a la que hace alusión el Capitán-Jefe de la Policía Armada podían encontrarse algunos de los miembros de la Iglesia Cubana y de los posteriores integrantes de CL. Afirmación que hacemos en base a la juventud de sus integrantes.

22 CALZADA FIOL, Alfonso: La verdad sobre "el Corredera... La ejecución de Juan García no solo produjo una concienciación entre elementos de la oposición, sino que también fue una experiencia muy rica. Muchos sectores se unieron para evitar la ejecución, incluyendo a hombres del régimen como el presidente del Cabildo de Gran Canaria o el Obispo de la Diócesis de Canarias, creándose una primera experiencia de "lucha interclasista".

23 LÓPEZ TRUJILLO, Zebensui: Imaginar..., pp. 67-68.

24 Testimonio de Fernando Sagaseta, citado en MILLARES CANTERO, Sergio: Fernando Sagaseta..., p. 116.

25 SUÁREZ CABRERA, Carlos: Mañana será mejor, Las Palmas de Gran Canaria, Anroart Ediciones, 2006, pp. 80-81. Estas charlas y reuniones eran comunes para muchos de los miembros de CL desde su pertenencia a la Iglesia Cubana.

26 AHPCE, Canarias, jacquet 12, p. 4. 


\section{Tagoror de Gran Canaria}

A la altura de noviembre de 1960, según una carta entre miembros del PCE, los integrantes de la organización eran simpatizantes del partido ${ }^{27}$. Con CL colaboraron las dos ramas que existían dentro del PCE en ese momento en Las Palmas de Gran Canaria, asesorándoles "los oficialistas" de Germán Pírez en el plano ideológico; mientras que del grupo del barrio de Arenales, compuesto por jóvenes entusiastas, surgió la mayoría de la propaganda y los agitadores urbanos, siendo absorbido en la práctica por $\mathrm{CL}^{28}$. Asimismo, se afirmaba en el verano del año siguiente que dentro de CL cooperaban

un elevado número de hombres y mujeres de las más diversas condiciones sociales e ideologías, cuya única bandera es la canariedad y el sentimiento de solidaridad humana ${ }^{29}$.

No podemos perder de vista que CL fue un grupo nacido en torno a la ciudad de Las Palmas de Gran Canaria y que su vínculo fuera de este espacio concreto fue puntual. El caso más notorio, dejando al margen los intentos de constituir lazos con comunidades de emigrantes canarios en el exterior, fue el lazo mantenido con Tenerife a través de un abogado laboralista que a finales de los años 50 ya capitaneaba el recién resurgido movimiento obrero en la isla: Antonio Cubillo Ferreira.

Cubillo intervino directamente en la gestación del grupo, asistiendo a varias reuniones celebradas en Gran Canaria y en las que se reveló, como afirma Luis Alsó, en uno de los principales defensores de la vía independentista dentro de la estrategia contra el franquismo ${ }^{30}$. A pesar de su papel en la conformación inicial de CL, Cubillo se fue distanciando progresivamente a causa de los inconvenientes de la insularidad, la falta de una estructura organizativa mínima y por un alejamiento ideológico cada vez más acusado con los militantes de Las Palmas, en la medida que éstos iban asumiendo progresivamente elementos procedentes del ideario del $\mathrm{PCE}^{31}$.

Por su parte, la relación de Cubillo con los comunistas, que, en el caso de Tenerife, eran mucho menos numerosos y activos, fue bastante menos estrecha. Evidentemente, el PCE se dio cuenta del potencial que tenía Cubillo como enlace con la clase obrera, ya que se estaba ocupando de defender a sectores de trabajadores afectados por la reconversión tecnológica y la monopolización de los sectores productivos. No obstante, Cubillo mantuvo siempre una actitud de cierta distancia para evitar que su despacho fuera vinculado con los comunistas, aunque aprovechó, siempre que pudo, los recursos que el partido le ofrecía.

\footnotetext{
27 AHPCE, Canarias, jacquet 9, p. 1.

28 MILLARES CANTERO, Agustín; DOMÍNGUEZ PRATS, Pilar, “La 'cuestión nacional' entre los comunistas grancanarios...", pp. 154-157.

29 AHPCE, Canarias, jacquet 10, p. 2. Esta idea es sostenida en otros documentos elaborados por dicho movimiento, como podría ser, por ejemplo, el siguiente: AHPCE, Canarias, jacquet 12, p. 4.

30 Luis Alsó. Entrevista concedida a Sergio Millares, recogida en MILLARES CANTERO, Sergio: Fernando Sagaseta..., pp. 131-132.

31 CABRERA ACOSTA, M. Á.; LÓPEZ TRUJILLO, Z.: “Antonio Cubillo...”, pp. 228-229.
} 
En diciembre de 1960, Cubillo viajó a París para reunirse como miembro de CL con la cúpula del PCE en el exilio. Este primer encuentro se saldó con la constatación de las primeras divergencias entre ambos en cuanto a los derechos nacionales de Canarias. No obstante, estas discrepancias terminarán por entibiarse hasta la ruptura total de la relación entre el PCE y Cubillo, de manera que los contactos entre CL y el Comité Central se mantendrán directamente con los militantes grancanarios ${ }^{32}$.

En el mes de octubre de 1961 ya se encontraba formado el Tagoror de Gran Canaria, que era quien firmaba las misivas enviadas por el movimiento, lo que da idea del primer intento por dotarse de cierta organización. En este año CL creó dos frentes, uno político, formado por los miembros del movimiento; y otro obrero, encabezado por el abogado laboralista Carlos Suárez, que trabajaría de forma independiente sin relación formal con CL. Este abogado fue asesorado por Antonio Cubillo, durante una estancia en su despacho de Santa Cruz de Tenerife, donde aprendió el sistema de las igualas ${ }^{33}$. En este frente jugó un papel importante Arturo Cantero Sarmiento, que atrajo a sus compañeros de la Compañía Insular de Nitrogenados SA, CINSA, hasta el despacho laboralista, según la estrategia adoptada. Este fue el primer colectivo obrero asesorado y defendido por el despacho recién abierto por Carlos Suárez, mientras que después vinieron los trabajadores de varias empresas de la ciudad como los de la patronal de autobuses urbanos de Las Palmas de Gran Canaria, los portuarios y los empleados de la fábrica Rumbo, que se dedicaba a la manufactura del tabaco ${ }^{34}$.

En Canarias, como ya apuntara el historiador Miguel Ángel Cabrera, el resurgimiento de la actividad sindical iría estrechamente ligada al proceso de reconstitución política que se estaba produciendo, donde "...la actividad de ambos [movimientos] se solapa continuamente y estructuras organizativas y dirigentes son, en gran medida, compartidos" 35 . Debido a que el PCE se encuentra entre 1961 y 1964 en un período de reorganización, empezado en parte por la actividad desplegada por $\mathrm{CL}^{36}$, durante la existencia de Canarias Libre el movimiento obrero es organizado y dirigido por los militantes nacionalistas. Por lo que no fue hasta 1964 cuando la Oposición Sindical Obrera empezaba su actividad en Las Palmas de Gran Canaria, de mano de los mili-

32 Ibidem, pp. 228-230.

33 Las igualas consistían en su base en una relación contractual entre el abogado y los trabajadores mediante la cual el letrado se comprometía a defenderlos en el terreno laboral-judicial a cambio de una cuota mensual, que funcionaba, a su vez, como caja de resistencia con la que hacer frente a la pérdida del salario por huelga o despido y que servía para abonar las multas impuestas en el desarrollo de esa actividad sindical. Para ampliar información sobre las mismas recomendamos la lectura de los siguientes trabajos: CABRERA ACOSTA, Miguel Ángel: "El resurgimiento del movimiento obrero canario y la repercusión de las huelgas de Asturias", en Rubén VEGA GARCÍA (coord.): El camino que marcaba Asturias. Las huelgas de 1962 en España y su repercusión internacional, Gijón, Ediciones Trea, Fundación Juan Muñiz Zapico, 2002, pp. 221236; LÓPEZ TRUJILLO, Zebensui: Imaginar..., pp. 58-59.

34 SUÁREZ CABRERA, Carlos: Mañana será mejor..., pp. 82-99; MILLARES CANTERO, Sergio: Fernando Sagaseta..., p. 130; entrevista realizada por Néstor García Lázaro a Arturo Cantero Sarmiento (17$\mathrm{V}-2010)$.

35 CABRERA ACOSTA, Miguel Ángel: "El resurgimiento del movimiento obrero canario...”, pp. $227-$ 228.

36 MILLARES CANTERO, Agustín; DOMÍNGUEZ PRATS, Pilar, "La 'cuestión nacional' entre los comunistas grancanarios...”, pp. 154-158; GARCÍA LÁZARO, Néstor: Las “escrituras criminales” en el contexto de la lucha por las libertades: teoría y práctica en Canarias entre 1959 y 1982, Las Palmas de Gran Canaria, Universidad de Las Palmas de Gran Canaria, Tesis Doctoral inédita, 2013, pp. 97-100. 
tantes del PCE, y de algunos antiguos miembros de CL, entre los que se encontraba el abogado Carlos Suárez, integrados ahora en el Partido Comunista, momento en el que comienza a consolidarse el movimiento obrero en la isla de Gran Canaria ${ }^{37}$.

Los apoyos a CL, así como a su organización, no se circunscribían al Archipiélago Canario, sino que desde los comienzos traspasaban sus fronteras. Teniendo el propio grupo residente en las Islas interés porque así fuera. Desde finales de 1960 contaba con apoyos en Tánger y Venezuela, donde estaban organizados y hacían propaganda; al mismo tiempo que intentaban contactar con el Comité Central del PCE para emitir desde Radio Praga ${ }^{38}$.

En agosto de 1961 enviaban una serie de cartas a los canarios residentes en el continente americano ${ }^{39}$, en la que se les pedía que se reunieran con sus compatriotas para formar un "Círculo o Peña de Canarias Libre" que encausara el esfuerzo de los emigrados y exiliados. En ese momento solo se les pedía dos cosas: difusión del movimiento "liberador de tu patria" y financiación del mismo. Se les escribía que estaba próxima la visita de miembros de CL a América para recoger el fruto de las simpatías y esfuerzos de todos los buenos canarios. Pidiéndoles en última instancia que lucieran en sus casas la bandera del movimiento, cuyos colores eran los siguientes: amarillo, azul y blanco, en tres barras verticales ${ }^{40}$. La única respuesta a estas misivas la recibieron del hermano de uno de los miembros de CL, que residía en Cuba, al que se le propuso la creación no ya de un círculo o una peña, sino de una Delegación Exterior de Canarias Libre. Las funciones que se le encomendaban eran las siguientes: creación de un clima de simpatía hacia la causa de la independencia de Canarias, recoger el dinero de los canarios de América y ponerse en contacto con las colonias canarias de México y Venezuela, facilitándosele una dirección en este último país. También se le preguntaba sobre la posibilidad de que imprimiera los estudios que se le habían enviado y enviarían desde Canarias para posteriormente distribuirlos en América e introducirlos en las islas. Al mismo tiempo, se le pedía que luciera en su vivienda la bandera, escribiendo sobre la misma el siguiente rótulo: "DELEGACIÓN DE CA-

37 Respecto a la propaganda de la Oposición Sindical Obrera en Las Palmas de Gran Canaria véase, GARCÍA LÁZARO, Néstor: Las “escrituras criminales” en el contexto..., especialmente las pp. 254-255, 547. Mientras que sobre el movimiento obrero en Canarias en este período CABRERA ACOSTA, Miguel Ángel: "El resurgimiento del movimiento obrero canario...", pp. 221-236; QUINTANA, Francisco: "Conflictos laborales y oposición sindical en Las Palmas, 1961-1973” en Javier TUSELL, Alicia ALTED, Abdón MATEOS (Coords.): La oposición al régimen de Franco. Estado de la cuestión y metodología de la investigación. Actas del Congreso Internacional que, organizado por el Departamento de Historia Contemporánea de la UNED, tuvo lugar en Madrid, del 19 al 22 de octubre de 1988 Tomo I, volumen 2. Madrid, Universidad Nacional a Distancia, 1990, pp. 85-88. Sobre la relación entre la Oposición Sindical Obrera y las Comisiones Obreras recomendamos el trabajo realizado por Francisco Erice donde explica este proceso. ERICE, Francisco: "La política sindical del PCE en los orígenes de las Comisiones Obreras: las confusiones en torno a la OSO", en Manuel BUENO, Carmen GARCÍA y José HINOJOSA (coords.): Historia del PCE. I Congreso, 1920-1977, Madrid, Fundación de Investigaciones Marxistas, vol. II, 2007, pp. 107-120.

38 AHPCE, Canarias, jacquet 9, p. 1.

39 Suponemos, basándonos en el caso de Cuba, que estos canarios residentes en América eran familiares y amigos de los miembros de CL en Canarias. A pesar de estos vínculos personales, la correspondencia muestra que los canarios-americanos desconocían la autoría personal de las misivas.

40 AHPCE, Canarias, jacquet 12, p. 5. 
NARIAS LIBRE!" ${ }^{41}$. En un llamamiento a todos los pueblos del mundo, realizado por el movimiento nacionalista canario, y fechado en diciembre de 1961, se escribía que pronto contarían en un país extranjero con un Comité que dirigiría la lucha iniciada por la libertad del Archipiélago ${ }^{42}$.

\section{Hombre Canario}

Canarias Libre, en palabras del movimiento, había sido un sentimiento difuso durante muchas generaciones, del que solo se llegó a tomar conciencia, "del modo más lúcido", en esos años debido a las circunstancias políticas concretas que las Islas estaban padeciendo. De este modo, para CL, lo único que se estaba haciendo era traducir "políticamente una legítima reivindicación"43, que a pesar de hundir sus raíces en el tiempo, no se había concretado hasta este momento, en el que la situación social, económica y política que imponía el régimen franquista en el Archipiélago, lo habían hecho aflorar ${ }^{44}$.

A causa de la dictadura imperante en España, dicho movimiento se consideraba nacionalista de un modo circunstancial y transitorio, ya que entendían que no podía ser ajeno al proceso de integración que el mundo imponía al género humano (internacionalismo $)^{45}$. En este sentido, consideraban que este proceso de independencia contaba con claras diferencias con lo ocurrido en América durante el siglo XIX. Canarias, al retrasarla por no existir una burguesía poderosa en aquella centuria, "va a independizarse por causa de la miseria social" y de la mano de "los campesinos y obreros, intelectuales y pequeñoburgueses". Por tanto, la lucha emancipadora partía de cero, sin ningún motivo romántico, "sino la más firme convicción racional de ser necesaria e históricamente inevitable" 46 .

Este nacionalismo estaba exento de xenofobia irracional, aunque esto no es óbice para mantenerse alerta ante injerencias externas ${ }^{47}$. De esta manera, sostienen, es un error pensar que dicho movimiento repudia a todo el pueblo español. Su repulsa va directa a un grupo económico que explota la situación política en su propio beneficio. Esto convierte en víctimas de este grupo de "desalmados", bajo este punto de vista,

41 AHPCE, Canarias, jacquet 12, pp. 3-4. Estos estudios parece ser que versaban sobre economía, y que serían ampliaciones de los temas tratados en las misivas conservadas en el AHPCE.

42 AHPCE, Canarias, jacquet 10, p. 3.

43 AHPCE, Canarias, jacquet 12, pp. 6-7; también en AHPLP, Gobierno Civil, Orden Público, Año 1961, Carta de un remitente desconocido al Alcalde de Firgas, octubre de 1961.

44 Sobre la situación socioeconómica de Canarias durante la inmediata posguerra y la década de 1950 recomendamos la lectura de los libros derivados de las Tesis Doctorales de Juan José Díaz y Ricardo Guerra. DÍAZ BENÍTEZ, Juan José: Anglofilia y Autarquía en Canarias durante la Segunda Guerra Mundial, Santa Cruz de Tenerife, Idea, 2008; GUERRA PALMERO, Ricardo A.: Sobrevivir en Canarias (1939-1959). Racionamiento, miseria y estraperlo, Santa Cruz de Tenerife, Idea, 2006.

45 AHPCE, Canarias, jacquet 12, p. 8; también en AHPLP, Gobierno Civil, Orden Público, Año 1961, Carta de un remitente desconocido al Alcalde de Firgas, octubre de 1961.

46 AHPCE, Canarias, jacquet 12, pp. 2, 3; AHPCE, Canarias, jacquet 10, p. 2.

47 AHPCE, Canarias, jacquet 12, pp. 8, 9; también en AHPLP, Gobierno Civil, Orden Público, Año 1961, Carta de un remitente desconocido al Alcalde de Firgas, octubre de 1961. 
tanto a los españoles como a los canarios, a pesar de que en las Islas se haya producido una "explotación colonial sin precedentes" 48 .

Para CL no había duda: Canarias era una colonia invadida por ejércitos españoles hacía cinco siglos. Fruto de la evolución política, social y económica del Archipiélago, unida a sus condiciones geográficas, surgió el "Hombre Canario" con características y personalidad propias ${ }^{49}$, descendientes de los colonizadores españoles y de la raza indígena que vivía en las Islas ${ }^{50}$. A pesar de que habían sido conquistadas a finales de la Baja Edad Media, lo que mantenía a Canarias en situación colonial eran los cambios que habían acaecido en el Estado español desde el comienzo de la Dictadura $^{51}$. En consecuencia, la relación de Canarias con la metrópoli era claramente desigual. Las condiciones de vida del isleño eran mediocres, inferiores a las medias universales y a las del resto del estado. Los poderes centrales habían conseguido, a través de decretos y leyes, que Canarias tuviera el nivel de vida más bajo, con una renta por habitante de ocho mil pesetas anuales (la mitad de la española) y el más alto porcentaje de analfabetos, que calculaban en un $30 \%$ de la población insular. Los gobiernos se habían preocupado en enviar "grandes remesas de gente peninsular", desvinculadas de los intereses isleños, que puestos al frente de los cargos de la administración había mantenido a Canarias narcotizada con promesas irrealizadas. Así, la metrópoli había estado de espaldas a la realidad canaria, sin saber ni querer cambiar el destino fatal que se vivía ${ }^{52}$.

En el plano económico, CL sostenía que las desigualdades y los perjuicios que se derivaban del dominio ejercido por la metrópoli se acrecentaban en las Islas por las políticas autárquicas del régimen, que perjudicaban gravemente a la economía insular muy necesitada de las conexiones exteriores. Y denunciaban esta situación colonial, utilizando como ejemplo el Puerto de Las Palmas, que a pesar de tener unas buenas condiciones debido a su situación geográfica, por cuestiones políticas, sostenían, no se permitía exportar los productos agrícolas básicos (plátanos y tomates) a los mercados consumidores europeos. Los comerciantes y exportadores ven sus productos sometidos a aranceles a la hora de negociar con la metrópoli, y sin embargo, a los puertos canarios llegan las mercancías metropolitanas desgravadas fiscalmente y sin necesidad de pagar arancel alguno a su arribo ${ }^{53}$.

Canarias solo había servido para crear riquezas que migraban a raudales hacia España, con olvido de las necesidades insulares. Ante este hecho, solo los canarios eran quienes podían cambiar ese "fatal destino", proclamando la independencia y tomando en sus "manos el gobierno y la dirección de nuestra economía y de nuestra política" ${ }^{54}$.

\footnotetext{
48 AHPLP, Gobierno Civil, sin clasificar.

49 AHPCE, Canarias, jacquet 12, p. 5.

50 AHPCE, Canarias, jacquet 10, p. 1.

51 AHPLP, Gobierno Civil, Orden Público, sin clasificar. Cfr. DÍAZ BENÍTEZ, Juan José: Anglofilia y Autarquía en Canarias...; GUERRA PALMERO, Ricardo A.: Sobrevivir en Canarias...

52 AHPCE, Canarias, jacquet 12, p. 5; AHPCE, Canarias, jacquet 12, p. 4; AHPCE, Canarias, jacquet 10 ,

53 AHPCE, Canarias, jacquet 10, pp. 1-2.

54 AHPCE, Canarias, jacquet 12, p. 4.
} pp. 1-2. 
Por lo tanto, CL quería incorporarse a "la lucha entablada por todas las comunidades humanas sojuzgadas", uniéndose a los pueblos de África, América, Asia y Oceanía, que surgían en esos momentos a la vida ${ }^{55}$. El Archipiélago era considerado un país geográficamente africano al encontrarse "a más de mil kilómetros de la metrópoli peninsular y a escasa distancia del continente que ha despertado". Debiendo África prestar la máxima ayuda a Canarias en su lucha ${ }^{56}$.

La estrategia utilizada para conseguir el fin de la emancipación pasaba por la posibilidad de una lucha armada, y de la internacionalización del conflicto, para ganar adeptos a la causa de la independencia, además de la labor de propaganda en el interior de las Islas.

El uso de la violencia fue barajada como una posibilidad, al igual que lo hacía en estos años la organización nacionalista vasca Euskadi Ta Askatasuna ${ }^{57}$. Esto se debía en gran medida al impacto que la revolución cubana tuvo sobre los integrantes del movimiento, según se desprende de una carta fechada el 27 de octubre de 1961 dirigida a un canario residente en Cuba. La lucha armada en Canarias, planteaban, debido a su reducida superficie, al no encontrarse formada una conciencia patriota en las masas campesinas y carecer de medios para llevarla a cabo, la consideraban prácticamente imposible y suicida. Sin embargo, eran conscientes que para el "parto nacional" sería necesario recurrir a las armas, debido a la situación de dictadura militar en la que vivían. Además, ésta tendría que consistir en una serie de golpes por sorpresa que les permitiera adueñarse de todos los puntos importantes por unos días, para bien obtener de la ONU "el mantenimiento de un statu quo que obligue a la metrópoli a entablar unas negociaciones" 58 , o bien recibir ayuda bélica para mantener una lucha armada con probabilidades de victoria: "Canarias Libre tiene la legítima aspiración de obtener la autodeterminación de este archipiélago atlántico sin necesidad de recurrir al uso de la violencia" ${ }^{59}$, pero si se vieran obligados a utilizarla el único responsable de sus consecuencias sería el régimen español que les oprimía.

Mientras tanto, era necesario ir preparando en el extranjero un ambiente propicio a la lucha emancipadora de Canarias, que tendría que apoyarse en el principio de la autodeterminación de los pueblos, ya que despertaba muchas simpatías, sinceras o fingidas, en todo el planeta. Los países que estimaban que más podían ayudar en la realización de dicha tarea eran los africanos y los latinoamericanos, principalmente los "neutralistas". Los primeros, por ser islas geográficamente africanas; mientras que los segundos, por ser un "país históricamente ligado a todas las repúblicas latinoamericanas, pues mucha sangre isleña corre por las venas criollas"; por tanto, veían comprensible y justificado que cualquier país de dicho continente fuera portavoz del anhelo de independencia de Canarias. Sin embargo, consideraban preciso que los países socialistas no debían aparecer como los más señalados defensores de la

55 AHPCE, Canarias, jacquet 12, pp. 7-9; también en AHPLP, Gobierno Civil, Orden Público, Año 1961, Carta de un remitente desconocido al Alcalde de Firgas, octubre de 1961.

56 AHPCE, Canarias, jacquet 10, p. 1; AHPCE, Canarias, jacquet 12, p. 2.

57 Cfr. FERNÁNDEZ SOLDEVILLA, Gaizka, LÓPEZ ROMO, Raúl: Sangre, votos, manifestaciones: ETA y el nacionalismo vasco radical (1958-2011), Madrid, Tecnos, 2012.

58 AHPCE, Canarias, jacquet 12.

59 AHPCE, Canarias, jacquet 10, p. 2. 
causa canaria, por ese momento, ya que ello tendría fatales consecuencias para el movimiento por cuanto crearía el recelo de los medios capitalistas y tendría resultados beneficiosos para la dictadura franquista. En esta labor colaborarían las Delegaciones Exteriores de Canarias Libre, antes mencionadas ${ }^{60}$.

El último paso dado por el grupo nacionalista fue la redacción de un llamamiento "A todos los pueblos del mundo", en el que se explicaba la situación colonial de las Islas, y de cómo ésta afectaba a la población isleña (problema del agua, carencia de viviendas, analfabetismo, etc.), con olvido de las necesidades propias del Archipiélago. En este llamamiento se pedía la ayuda de todos los países del mundo para que favoreciesen la autodeterminación política de Canarias, ya que sin su ayuda dicha tarea sería complicada. El llamamiento debía ser difundido por todas las agencias internacionales de noticias entre los días 29 y 30 de diciembre de 1961, dándosele prioridad a las occidentales que tendrían que ser las primeras en su publicación ${ }^{61}$.

En cuanto a su constitución política, los miembros de CL sabían que no había nada definitivo en la historia y que la constitución definitiva estaría ligada íntimamente a la "praxis de la lucha emancipadora por la que habremos de pasar", y por lo tanto, "al influjo de las fuerzas sociales que contribuyan más decisivamente al logro del afán patriótico", aunque la corriente se movía hacia un socialismo republicano ${ }^{62}$, queriendo elevar a estas islas dentro de "las naciones más progresistas del mundo" 63 .

En el nuevo estado canario, el principal fin sería la desaparición inmediata de la miseria "vergonzante" de los campesinos y obreros, sustituida por "la equitativa distribución de la renta del archipiélago". Las relaciones entre hombres y mujeres se basarían en la solidaridad y cooperación, en lugar de la dominación o sumisión, como se fundaban en aquel momento. Poseyendo y disfrutando todos del "mismo inalienable derecho a la felicidad y a la libertad". Esto se conseguiría cambiando el carácter irracional y caótico de la economía isleña, que sería "urgentemente reemplazado" por una economía planificada "que represente el esfuerzo racional, rígido y armónico de la comunidad entera", encontrándose subordinado el "mecanismo económico" a los propósitos de felicidad. También se lucharía contra el abuso y corrupción de la administración local, que junto a la miseria de los campesinos y obreros, formaba el primer plano "envilecedor y dramático" de los campos y pueblos de Canarias. Debido a que una de las consecuencias de la situación colonial eran las altas tasas de analfabetismo, en el nuevo Estado se fomentaría la difusión de la cultura, estimándola como "pilar fundamental para la construcción de la comunidad de hombres libres del futuro que ha de constituirse en este Archipiélago"64.

En cuanto al papel que asumirían las Islas en un escenario internacional marcado por la Guerra Fría, sería el de una "neutralidad positiva". Este tipo de neutralidad no era indiferente, sino libre de prejuicios, que en cada ocasión les haría estar al lado de la felicidad de los pueblos, de la vida, de la paz y de la verdad; que se oponían a la

60 AHPCE, Canarias, jacquet 12, p. 2.

61 AHPCE, Canarias, jacquet 10. Posiblemente este llamamiento no llegó a ser difundido.

62 AHPCE, Canarias, jacquet 12, p. 3.

63 AHPCE, Canarias, jacquet 12, p. 6.

64 AHPCE, Canarias, jacquet 12, p. 8; también en AHPLP, Gobierno Civil, Orden Público, Año 1961, Carta de un remitente desconocido al Alcalde de Firgas, octubre de 1961. 
opresión, la muerte, la violencia y la mentira. Así, pedía que los países descolonizados, que surgían a la vida política en esos años pudieran colaborar libre y espontáneamente "a la formación de un mundo desembarazado de la miseria y de la ignorancia"; siendo neutrales en la lucha entablada por las dos grandes potencias que "tratan de dirigir el destino de la humanidad" ${ }^{\prime 65}$.

\section{Viva Canarias Libre}

El Gobernador Civil de Las Palmas informaba en la memoria anual correspondiente al año de 1962 que el ambiente político en dicha provincia no era plenamente satisfactorio, a pesar de las circunstancias favorables en que se desenvolvía su economía dicho año en comparación con los anteriores. Ello se debía, según el informe, a la "creencia bastante arraigada de que por el Gobierno no son debidamente atendidos y estudiados los graves problemas que se plantean" en dicho territorio. Muchos de ellos eran vitales para su normal desarrollo, y sin embargo su resolución se retrasaba, "al seguir trámites oficiales interminables (...) debido al centralismo absoluto que existe para todo lo oficial".

A pesar del malestar existente en las capas populares y en la clase media, en ese descontento se percibía el deseo de que el Gobierno acertara no solo en resolver los problemas acuciantes de la vivienda y el abaratamiento de la vida, sino que las disposiciones que se ordenaran para resolver dichos problemas se realizaran vigilando su cumplimiento. Por tanto, según la máxima autoridad civil en Las Palmas, no existía "gran preocupación, al menos hasta ahora, porque las inquietudes sociales que puedan existir sean recogidas y manejadas políticamente con fines subversivos"

Tenemos que recordar que en este año los trabajadores de todo el estado aún no se habían beneficiado del crecimiento económico que se estaba produciendo y que era pregonado por la propaganda del poder político franquista ${ }^{67}$. En Canarias esta situación llegaba a situaciones insostenibles, en la que los precios de los vegetales y los productos diarios estaban incrementándose. La diplomacia británica en un informe económico sobre el Archipiélago, concerniente a la primera mitad del año 1961, veía probable que para el invierno la asistencia social tendría que ser dada a las capas populares en forma de distribución de alimentos mediante la caridad diocesana ${ }^{68}$.

Esta preocupación venía porque los movimientos sociales al intentar influir en el mundo de lo político tienen entre sus tareas esenciales

definir e interpretar los problemas sociales y las injusticias, de modo y manera que se logre convencer a una audiencia amplia y muy diversa de la necesidad y utilidad de

65 AHPCE, Canarias, jacquet 12, pp. 8-9; también en AHPLP, Gobierno Civil, Orden Público, Año 1961, Carta de un remitente desconocido al Alcalde de Firgas, octubre de 1961.

66 AGA, Gobernación, Memorias de los Gobiernos Civiles, Memoria anual del Gobierno Civil de Las Palmas de Gran Canaria. Año 1962, apartado 1.1.3.- Cuestiones políticas y sindicales.

67 MOLINERO, Carme: "Una gran apuesta: la oposición política...,, p. 261.

68 TNA, FO 371/160772, Canary Islands: Economic report: January-June, 1961, p. 2. 
emprender acciones colectivas para corregir estas deficiencias. Definiendo los problemas y las causas; y la estrategia a seguir para solventar el problema ${ }^{69}$.

Y justamente, fue una de las tareas en las que más empeño puso el movimiento, "cuyo objetivo era lograr la independencia de las Islas mediante la creación del clima y ambiente de malestar apropiado" 70 .

Para dicha tarea, CL utilizó el sistema de captación personal y el de la "propaganda"71. Esta última, durante el año de 1961, fue impresa con una imprenta infantil (imprentilla de mano) comprada por Andrés Alvarado Janina, con la que junto a Arturo Cantero confeccionó "cierto número de octavillas"72. Este método, según CL, tenía efectos espectaculares, pero resultaba difícil mantener la periodicidad de la misma que era necesaria para que resultara eficaz. Las imprentas de las que se valían no podían dar seriedad a la propaganda que realizaban, "con textos sumamente reducidos que no pueden inspirar mayor confianza"73. Por ello, veían necesario conseguir una multicopista, que terminó siendo construida por Armando León Herrera, y en la que se imprimió, como mínimo, un manifiesto que fue difundido por los miembros de la organización en el mes de enero de $1962^{74}$.

La primera octavilla que difundieron fue una que se lanzó el Jueves Santo de 1961 con el texto: “19.000 presos políticos se pudren en España mientras tú estás en el carnaval de los curas". No obstante, la octavilla no iba firmada con las siglas de CL como fue habitual posteriormente y los miembros de CL no han reconocido expresamente que ésta fuera la primera hoja que el grupo esparciera por la ciudad, atribuyendo la autoría a un grupo del barrio capitalino de San José, liderado por Andrés Alvarado $^{75}$. Sin embargo, sus características formales y que además así aparece recogido en la sentencia de la causa que se les abrió posteriormente, parecen relacionarla directamente con el grupo nacionalista ${ }^{76}$. Según Carlos Suárez, tuvo una repercusión

69 MCCARTHY, John D., SMITH, Jackie y ZALD, Mayer N.: "El acceso a la agenda pública y a la agenda del gobierno: medios de comunicación y sistema electoral” en Doug MCADAM, John D. MCCARTHY, Mayer N. ZALD (eds.): Movimientos sociales: perspectivas comparadas. Oportunidades políticas, estructuras de movilización y marcos interpretativos culturales, Madrid, Istmo, 1999, p. 413.

70 Tal y como reconocieron la autoridad militar que los juzgó. SENTENCIA, folios números 108 y 109 de la causa $\mathrm{n}^{\mathrm{0}} 78$ de 1962 .

71 Para una visión de conjunto sobre la propaganda ilegal en la provincia de Las Palmas durante el tardofranquismo remitimos al artículo realizado por Néstor García Lázaro sobre la misma. GARCÍA LÁZARO, Néstor: "Escrituras contestarias en contextos dictatoriales. Las Palmas durante el tardofranquismo (1959-1975)", Hispania. Revista española de Historia, [en prensa]

72 Sentencia, folios números 108 y 109 de la causa n 78 de 1962; CANTERO SARMIENTO, Arturo: Mujeres canarias contra la represión, Centro de la Cultura Popular Canaria, La Laguna, 1.997, p. 122.

73 AHPCE, Canarias, jacquet 12, p. 1.

74 Sentencia, folios números 108 y 109 de la causa no 78 de 1962. AHPLP, Gobierno Civil, caja 684, escrito reservado del Gobernador Civil de Las Palmas al Iltmo. Sr. Director General de Política Interior, de fecha 3 de febrero de 1962. Desconocemos si la construcción de la multicopista se debió a la imposibilidad de reunir dinero para realizar la compra de una, o ante el peligro que entrañaba la adquisición de una multicopista de manera legal, ya que se encontraban numeradas, y el régimen ejercía un estrecho control sobre las mismas.

75 GARI HAYEK, Domingo: Historia del Movimiento Canarias Libre..., pp. 90-91; MILLARES CANTERO, Sergio: Fernando Sagaseta..., p. 123; SUÁREZ CABRERA, Carlos: Mañana será mejor..., p. 80. Una excepción es el testimonio de Arturo Cantero en su libro Mujeres canarias..., p. 114.

76 SENTENCIA, folios números 108 y 109 de la causa nº 78 de 1962. 
espectacular en la ciudad y les abrió los ojos acerca del poder de la agitación ${ }^{77}$. Para ello, se dieron cuenta de que tenían que hacer análisis y que para que éstos tuvieran consistencia necesitaban estudios que proporcionaran datos sobre la realidad que cuestionaban $^{78}$.

Los textos de las octavillas condensaban las ideas expuestas en las cartas. En ellas se exhortaba a romper el yugo fascista, para dejar de ser esclavos; la miseria del canario después de 478 años, siendo una clara alusión a la conquista de las Islas, y cómo después de 25 años "miles de obreros ganan 900 pesetas al mes", pidiendo justicia por ello. En otra se unía el bajo salario del agricultor, la mísera vivienda, y la falta de escolarización de los niños "en 22 años de paz fecunda", aludiendo a la propaganda que el régimen hacía de la "paz franquista". En las últimas se pedía que los canarios despertaran y lucharan por su patria; así como intentaban convencer a los obreros y campesinos de su fuerza si se unían a sus compañeros de trabajo, a los que avisarían del día de una futura huelga. Todas ellas terminaban dando un "Viva Canarias Libre"79. Así ponían su atención en movilizar a las capas populares, obreros y campesinos, que según ellos eran los más castigados económicamente por la situación política reinante, y en las que estaban apreciando "progresos sumamente alentadores" mediante el sistema de captación personal ${ }^{80}$.

Otros medios que utilizaron para expandir sus ideas, así como para constatar su presencia en el espacio público, fueron los siguientes: envíos de cartas, peticiones de "Canarias Libre" en los bares y realización de pintadas.

Sabemos que el movimiento realizó envío de cartas a los canarios residentes en América durante el segundo semestre de $1961^{81}$, pero poco conocemos sobre el uso de este recurso dentro de las Islas. Sólo contamos con una misiva enviada al Alcalde de Firgas, y que éste remitió al Gobernador Civil para que tuviera constancia de la misma. En el sobre no puede apreciarse la fecha del envío, pero sí consta el remitente que era alguien real para no crear sospechas, pero que no tendría vinculación con Canarias Libre. En el texto de la misma se hacía alusión a los problemas que padecía Canarias, y se pedía la colaboración para conseguir la emancipación de la misma. Desconocemos si llegaron a mandarse más copias al resto de alcaldes de los municipios de las Islas, a otras personas o instituciones ${ }^{82}$.

Según Arturo Cantero, otra de las estrategias utilizadas era la de ir por los bares de la ciudad pidiendo un "Canarias Libre". Éste se pedía a viva voz en todos los bares,

77 SUÁREZ CABRERA, Carlos: Mañana será mejor..., p. 80.

78 MILLARES CANTERO, Sergio: Fernando Sagaseta..., p. 124.

79 Fragmentos de la Sentencia, folios números 108 y 109 de la causa $n^{\circ} 78$ de 1962 . Un extracto, en donde aparecen algunos de estos textos, puede leerse en el Extracto de una copia del Consejo de Guerra contra los militantes de Canarias Libre, transcrito en GARÍ HAYEK, Domingo: Historia del Movimiento Canarias Libre..., p. 143.

80 AHPCE, Canarias, jacquet 12, p. 1.

81 Cuyo contenido expusimos en el apartado anterior, y las cuáles se conservan en el AHPCE.

82 AHPLP, Gobierno Civil, Orden Público, Año 1961, Carta de un remitente desconocido al Alcalde de Firgas, octubre de 1961. Véase GARCÍA LÁZARO, Néstor: "El movimiento Canarias Libre: génesis del nacionalismo canario", en Ángeles BARRIO ALONSO, Jorge HOYOS PUENTE, Rebeca SAAVEDRA ARIAS (eds.): Nuevos horizontes del pasado: culturas políticas, identidades y formas de representación, Santander, Publican, Ediciones de la Universidad de Cantabria, 2011 (cd). 
abandonando la prudencia necesaria que exige la clandestinidad. La bebida consistía en la mezcla de ron con algún refresco, principalmente canario, para diferenciarlo del "Cuba Libre" que era a base de ron y cola ${ }^{83}$.

El otro recurso utilizado por el movimiento fue la realización de pintadas mediante tizas de fabricación casera. Éstas consistían básicamente en escribir sobre diversos soportes las iniciales de la organización. Según recuerdan sus miembros, las pintadas proliferaban por toda la ciudad y llegó un momento en el que incluso colaboraban espontáneos que actuaban por libre ${ }^{84}$.

A medida que se sucedían las acciones de propaganda, éstas iban ganando en espectacularidad, poniendo en riesgo a una organización poco o nada acostumbrada a la clandestinidad. Un ejemplo de este aumento de la magnitud de las acciones fueron las pintadas en el Estadio Insular. Los detalles fueron minuciosamente estudiados por el movimiento, eligiéndose la jornada del domingo 4 de marzo de 1962 para ello, ya que en ese día se jugaban dos encuentros trascendentales: en la sesión matutina se enfrentaban la Selección Juvenil de Las Palmas y la Cántabra; y en la vespertina, la Unión Deportiva Las Palmas y el Córdoba, en el que el equipo canario se jugaba el ascenso a la Primera División. La célula encargada de la pintada entró en el recinto durante la noche de la víspera. Según Arturo Cantero, la policía intentó retrasar el inicio del encuentro matutino para poder borrar las inscripciones, pero las personas que iban a presenciar el encuentro de los juveniles amenazaban con derribar las puertas de acceso al Estadio ${ }^{85}$. Según Sergio Hernández, el impacto visual de las pintadas fue tremendo, y cuando por la tarde se estaban comprando las entradas para el otro partido, "todo el mundo hablaba de eso" 86.

Sin embargo, el partido de la tarde distará mucho del anterior, quizás gracias al árbitro del encuentro. La Unión Deportiva necesitaba ganar para seguir teniendo opciones para conseguir el ascenso a la categoría superior, y el marcador le daba la ventaja por un gol hasta el minuto 89 , momento en el que el árbitro señala un penalti inexistente, según la afición, a favor del equipo visitante.

La afición grancanaria empezó a lanzar objetos dentro de la cancha que impidieron durante más de quince minutos que se lanzara la pena máxima por parte del Córdoba. Después, fuera del Estadio, y según testimonio de Arturo Cantero, se destrozaron los vehículos con matrículas peninsulares y se lanzaron objetos contra la Policía Armada y el propio coche en donde iba el Gobernador Civil de la provincia ${ }^{87}$. Al día siguiente la prensa local se hacía eco de estos sucesos, comentando que el árbitro había sus-

83 CANTERO SARMIENTO, Arturo: Mujeres canarias..., p. 114; testimonio de Arturo Cantero Sarmiento, recogido en MILLARES CANTERO, Sergio: Fernando Sagaseta ..., p. 137.

84 CANTERO SARMIENTO, Arturo: Mujeres canarias ..., pp. 91, 114; entrevista realizada por Domingo Garí a Jesús Cantero Sarmiento el 8-VI-1989, transcrita en GARÍ-MONTLLOR HAYEK, Domingo: Historia del movimiento Canarias Libre..., p. 141. Fragmentos de la SENTENCIA, folios números 108 y 109 de la causa $\mathrm{n}^{\circ} 78$ de 1962

85 CANTERO SARMIENTO, Arturo: Mujeres canarias..., pp. 90 - 92; GARÍ-MONTLLOR HAYEK, Domingo: Historia del movimiento Canarias Libre..., pp. 75 - 81 .

86 Entrevista realizada por Néstor García Lázaro a Sergio Hernández Ibrahim (3-III-2010).

87 CANTERO SARMIENTO, Arturo: Mujeres canarias..., pp. 90 - 93; entrevista realizada por Néstor García Lázaro a Sergio Hernández Ibrahim (3-III-2010); entrevista realizada por Néstor García Lázaro a Arturo Cantero Sarmiento (17-V-2010). 
traído lo que era ya una justa victoria de Las Palmas y que "el vergonzoso atropello provocó el mayor escándalo en la historia del fútbol canario, alterándose seriamente el orden público" 88 . Por otro lado, el Gobernador Civil, a pesar de negar la existencia de "movimientos disidentes", no pudo dejar de referirse a estos acontecimientos en la memoria de gestión de 1962, haciendo alusión a "grupos de opinión, no bien definidos, y reacciones de opinión ante hechos circunstanciales" 89.

Debido al éxito obtenido, CL repetirá la misma operación el domingo 25 de marzo de ese mismo año, pero las autoridades civiles habían aprendido la lección después de los "desórdenes públicos" ocurridos a principios de mes. Al encontrarse letreros con la inscripción "Viva Canarias Libre" en el interior del Estadio Insular se llamó al personal perteneciente al Cuerpo de Bomberos para que procediera a la eliminación de los mismos. El partido se retrasó, "ya que no se permitió el acceso del público hasta que no fueran desaparecidos los mismos", de este modo los asistentes no se percataron de lo sucedido y las pintadas no tuvieron trascendencia alguna ${ }^{90}$.

Ese mismo día sobre las ocho de la mañana dos individuos introducían por debajo de las puertas de las casas de la barriada de Guanarteme "hojas de propaganda subversiva" firmadas por CL. Según el Servicio de Información de la Guardia Civil, las personas que pudieron leerlas se mostraron pasivas sin hacer ningún comentario y sin darle importancia a los textos ahí escritos ${ }^{91}$.

\section{Desarticulación}

Los registros domiciliarios y posteriores detenciones comenzaron al día siguiente, lunes 26 de marzo, imponiendo el Gobernador Civil las pertinentes sanciones administrativas a algunos de los miembros del movimiento el día 29 de dicho mes ${ }^{92}$. Aunque no cayeron todos los integrantes del movimiento, ya fuera gracias a que algunos de los detenidos no dieron información en los interrogatorios, o por las repercusiones que podría tener la detención, proceso y encarcelamiento dentro del movimiento obrero, como podía ser el caso del abogado Carlos Suárez ${ }^{93}$. El día 6 abril en la Plaza de Las Palmas se procedió a ver y fallar la Causa Sumarísima número 78 de 1962 contra Fernando Sagaseta y ocho más, por el delito de rebelión militar ${ }^{94}$. Cumplién-

\footnotetext{
88 Diario de Las Palmas, 5 de marzo de 1962, p. 3.

89 AGA, Gobernación, Memorias de los Gobiernos Civiles, Memoria anual del Gobierno Civil de Las Palmas de Gran Canaria. Año 1962, s. p.

90 AHPLP, Gobierno Civil, Orden Público, Nota Informativa número 351 del Servicio de Información de la Guardia Civil. Enviada al Excmo. Sr. Gobernador Civil de Las Palmas el día 27 de marzo de 1962, con el asunto: sobre aparición de Hojas Clandestinas.

91 AHPLP, Gobierno Civil, Orden Público, Nota Informativa número 351 del Servicio de Información de la Guardia Civil. Enviada al Excmo. Sr. Gobernador Civil de Las Palmas el día 27 de marzo de 1962, con el asunto: sobre aparición de Hojas Clandestinas. Por lo general, en los testimonios de los miembros del Canarias Libre que se han publicado hasta el momento se suelen unir estas dos jornadas en una sola.

92 CANTERO SARMIENTO, Arturo: Mujeres canarias..., pp. 43-49, 115, 117, 122, 123; MILLARES CANTERO, Sergio: Fernando Sagaseta ..., pp. 140 -142.

93 SUÁREZ CABRERA, Carlos: Mañana será mejor..., pp. 81-85.

94 Un extracto de la misma puede leerse en GARÍ-MONTLLOR HAYEK, Domingo: Historia del movimiento Canarias Libre..., pp. 142-143.
} 
dose de esta manera las expectativas del movimiento, que sabía que tarde o temprano el Estado iba a utilizar todos los medios posibles para silenciarlos ${ }^{95}$.

Aunque el Gobernador Civil de Las Palmas negara la existencia de movimientos disidentes en la provincia, además de la posibilidad de que el malestar existente en la población fuese utilizado por grupos subversivos, hemos podido observar que las cosas fueron bien distintas. La Brigada Regional de Investigación Social, perteneciente a la Dirección General de Seguridad, destacó al finalizar el año la detención de CL, "con un cierto matiz separatista", que había realizado una intensa campaña propagandística, "con indiscutibles puntos de atracción para muchos elementos del país". De dicho sentimiento se obtuvo "una disminución patente", gracias a la rápida actuación policial, acción militar juzgadora, llegada de distintos Ministros que mostraron interés por los pobladores isleños ${ }^{96}$, estudio del Plan de Desarrollo de Canarias y aprobación de la llamada Ley de Aguas, pudiendo considerarse remitida en gran parte la expresada tendencia político-separatista ${ }^{97}$.

La detención y juicio militar de la cúpula dirigente de CL fue seguida de considerables muestras de apoyo popular. Siguiendo una de las máximas de la propaganda de CL,

cualquier cosa que puedas hacer, alguna palabra que puedas decir en contra de esta situación vergonzosa, no vaciles en realizarla; con ello cumples un deber y ayudarás a poner remedio a este odioso estado de $\cos ^{9}{ }^{98}$.

Recogiéndose muestras de solidaridad y adhesión espontánea al grupo y a su ideario. En ciertos sectores la caída de CL supuso una frustración tal que el discurso privado acabó aflorando en contextos propicios, al margen de las consecuencias de sus manifestaciones. En este sentido, conocemos el caso de un comerciante de 40 años que en un bar en el barrio de Vegueta, había dicho a unos sargentos del ejército que ahí se encontraban, "a viva voz y repetidas veces Viva Canarias Libre y que él antes que español era canario" 99 . En otro caso, un cambullonero de La Isleta, de 36 años, en el "Bar Los Tarahales" profirió en alta voz "Viva Canarias Libre" ante los clientes que allí se encontraban, entre los que había un teniente del ejército ${ }^{100}$. Y por último, un limpiabotas de 38 años de la barriada popular de Schamann, cuando se encontraba

95 En el llamamiento $A$ todos los pueblos del mundo, decían lo siguiente: "la actual administración metropolitana no vacilará en utilizar todos los recursos propios de su tiránico poder para reducirnos al silencio", AHPCE, Canarias, jacquet 10.

96 El historiador Domingo Garí ya vinculó la visita a Canarias del Ministro General del Movimiento, Solís Ruiz, con la incidencia que el movimiento tuvo dentro y fuera de las Islas. GARÍ-MONTLLOR HAYEK, Domingo: Historia del movimiento Canarias Libre..., p. 78.

97 AGA, Gobernación, Memorias de los Gobiernos Civiles, Memoria anual del Gobierno Civil de Las Palmas de Gran Canaria. Año 1962.

98 AHPLP, Gobierno Civil, Orden Público, Nota Informativa número 351 del Servicio de Información de la Guardia Civil. Enviada al Excmo. Sr. Gobernador Civil de Las Palmas el día 27 de marzo de 1962, con el asunto: sobre aparición de hojas clandestinas.

99 AHPLP, Gobierno Civil, caja 675, Escrito del Delegado Especial al Excmo. Gobernador Civil de Las Palmas, de fecha 5 de abril de 1962.

100 AHPLP, Gobierno Civil, caja 675, Escrito del Delegado Especial al Excmo. Gobernador Civil de Las Palmas, de fecha 7 de abril de 1962. 
por la tarde en un bar situado en la calle General Franco dijo las siguientes frases: "Viva Canarias Libre" y "que si Sagaseta estaba en la Cárcel, en la calle quedaban muchos más" 101 .

Estas tres situaciones, a pesar de tener aparentemente escasa entidad, dan idea de la dimensión social que tuvo CL y cómo ciertos sectores numerosos de la ciudad de Las Palmas de Gran Canaria interiorizaron los marcos interpretativos propuestos por el movimiento nacionalista.

La última muestra de solidaridad con los detenidos la llevaron a cabo los obreros de la empresa CINSA donde trabajaba Arturo Cantero, y consistió en la realización de unas pintadas en las inmediaciones de la fábrica. En ellas se pedía solidaridad con los mineros en huelga en Asturias, amnistía para el compañero detenido, así como llamaban a celebrar el $1^{\circ}$ de mayo ${ }^{102}$.

Los integrantes de CL durante su período en prisión ingresaron en el PCE. Algo que parece lógico cuando muchos de ellos tenían lazos de parentesco con los miembros del Comité Provincial del partido ${ }^{103}$. Por otro lado, la represión ejercida por el régimen no solo fue para acabar con el "sentimiento separatista", sino que también intentó debilitar al naciente movimiento obrero. Así, Arturo Cantero, que había ayudado a la toma de conciencia entre los compañeros de su empresa, fue incluido en la Causa Sumarísima, cuando llevaba tiempo sin tener relación con CL. Al regresar de la prisión, la Delegación Especial de la Dirección General de Seguridad se encargó de corroborar que no volvía a trabajar en CINSA, de donde había causado baja cuando fue condenado, al igual que descubrir cuál sería su nuevo domicilio ${ }^{104}$.

La llegada a Las Palmas de Gran Canaria de Fernando Sagaseta, considerado el cabecilla de la organización, se produjo en septiembre de 1965. En esas fechas ya todos los miembros habían dejado la prisión y regresado a Gran Canaria. Parecía que la única opción posible era la incorporación en el PCE de todos los integrantes del desarticulado movimiento y la aceptación de la línea impuesta por su dirección. Pero pensamos que este fue un proceso que no gustó a todos, y algunos intentaron seguir

101 AHPLP, Gobierno Civil, caja 688, Escrito del Delegado Especial al Excmo. Gobernador Civil de Las Palmas, de fecha 24 de abril de 1962.

102 AHPLP, Gobierno Civil, caja 672, Nota Informativa número 563 del Servicio de Información de la Guardia Civil. Enviada al Excmo. Sr. Gobernador Civil de Las Palmas el día 5 de mayo de 1962, con el asunto: Aparición de letreros murales subversivos. Sobre el movimiento obrero de Canarias en este período y la repercusión de las huelgas de Asturias, véase: CABRERA ACOSTA, Miguel Ángel: "El resurgimiento del movimiento obrero canario..., pp. 221-236.

103 Sobre este período véase MILLARES CANTERO, Sergio: Fernando Sagaseta..., pp. 161-202. CANTERO SARMIENTO, Arturo: Memorias de la prisión de Cáceres, Las Palmas de Gran Canaria-Santa Cruz de Tenerife, Centro de la Cultura Popular Canarias, 2010. Para las relaciones de parentesco entre los miembros del PCE y algunos de los de CL, véase CANTERO SARMIENTO, Arturo: Mujeres canarias... Algunos autores han tipificado a los comunistas grancanarios como un partido de familias comunistas, véase MILLARES CANTERO, Agustín DOMÍNGUEZ PRATS, Pilar: "Pocos, activos y abnegados: una tipificación de los comunistas en Gran Canaria (1961-1973)" en Manuel BUENO, Carmen GARCÍA y José HINOJOSA (coords.): Historia del PCE. I Congreso, 1920-1977, Madrid, Fundación de Investigaciones Marxistas, 2007, vol. II, pp. 195 - 211.

104 AHPLP, Gobierno Civil, caja 672, Escrito de la Delegación Especial de la D.G.S. al Excmo. Sr. Gobernador Civil, de fecha 31 de octubre de 1963, con el asunto Arturo Cantero Sarmiento. Esta cuestión ya había sido denunciada por Arturo Cantero en su libro CANTERO SARMIENTO, Arturo: Mujeres canarias...., pp. 143-147. Entrevista realizada por Néstor García Lázaro a Arturo Cantero Sarmiento (17-V-2010). 
con el proyecto "nacionalista". De este modo, el 23 de octubre de ese año cuando unos policías detuvieron a uno de los antiguos integrantes de CL por promover un altercado en una sala de fiestas, éste les grito, entre otras cosas, en el momento en que intentaban reducirlo: "Viva Canarias Libre e independiente" 105 . Al mes siguiente en las fachadas de distintas casas de Las Palmas de Gran Canaria aparecieron los textos "VIVA CANARIAS LIBRE" y las iniciales C.L., que fueron borrados rápidamente para que no tuvieran ninguna trascendencia en la población ${ }^{106}$.

\section{Conclusiones}

Canarias Libre constituyó el inicio del resurgimiento de la oposición política, sindical y nacionalista en Canarias, tras el golpe y posterior represión franquista. En el plano político, no solo se convirtió en la primera organización de oposición política contra el franquismo nacida de una nueva generación de opositores, sino que, al mismo tiempo, imprimió un nuevo ritmo a los grupos sobrevivientes de oposición, representados principalmente por las células del PCE en Las Palmas de Gran Canaria. En el terreno sindical, sus miembros crearon los primeros despachos laboralistas en las Islas, Antonio Cubillo en Tenerife y Carlos Suárez en Gran Canaria, teniendo un papel primordial en los inicios de la reconstitución del movimiento obrero insular.

El presente trabajo ha permitido profundizar en el conocimiento del programa político e ideológico de CL, que los trabajos anteriores, sostenidos fundamentalmente en el análisis de fuentes orales, no habían podido más que esbozarlas difusamente. Por el contrario, la nueva documentación disponible ha permitido comprobar que estas ideas eran de una gran complejidad y riqueza, teniendo como elementos básicos la influencia manifiesta del proceso descolonizador afroasiático y el americanismo (Revolución Cubana). De esta manera, CL articuló un discurso ideológico pivotado entre las ideas progresistas, definido por ellos como de "socialismo republicano", y un nacionalismo circunstancial, nunca dirigido contra el pueblo español, al que se ve también como afectado, condicionado a la consecución de la independencia y a la ruptura con la España de Franco. Para conseguirlo, proponían tres vías centrales: la acción diplomática, buscando el apoyo de las naciones del mundo; la propagandística, acercando el sentimiento de canariedad a la sociedad insular; y la lucha armada, como recurso complejo de aplicar en su actual situación, pero inevitable para conseguir sus objetivos. Y todo ello, sostenido con una lectura histórica en la que las Islas eran consideradas colonias españolas que no se habían emancipado por la falta de aspiraciones de una burguesía nacional, y que las actuales condiciones de dictadura habían avivado entre los sectores populares, intelectuales y pequeñoburgueses. Incluso, se podría afirmar que CL puso las bases de lo que vendrá más tarde con la

105 Sentencia 24/66 del Tribunal de Orden Público, de fecha 3 de febrero de 1966.

106 AHPLP, Gobierno Civil, legajo 164, Nota informativa número 1833 del Servicio de Información de la Guardia Civil. Enviada al Excmo. Sr. Gobernador Civil de la Provincia, de fecha 21 de noviembre de 1965, con el asunto Letreros murales subversivos. Sobre la "cuestión nacional" en el interior del Partido Comunista de España en Gran Canaria léase MILLARES CANTERO, Agustín y DOMÍNGUEZ PRATS, Pilar, "La 'cuestión nacional' entre los comunistas grancanarios..." 
formulación del independentismo africanista canario, y en la que volveremos a ver referenciados la mayor parte de estos elementos.

En cuanto a su impacto sociopolítico, CL proporciona un buen ejemplo de acceso por parte de los movimientos sociales a la agenda pública y del gobierno como plantean McCarthy, Smith y Zald, utilizando marcos interpretativos pobremente articulados que son difundidos de forma eficaz ${ }^{107}$. En el período de un año consiguieron que las autoridades españolas prestaran la atención que no habían prestado a Canarias a lo largo de la dictadura, forzando al régimen a articular toda una serie de medidas orientadas a contener un ambiente social que se había enrarecido a medida que las posiciones de CL se filtraban entre crecientes sectores sociales de la ciudad de Las Palmas.

\section{Bibliografía}

ALCARAZ ABELLÁN, José: La resistencia antifranquista en las Canarias Orientales (1939-1960), Las Palmas de Gran Canaria, El Museo Canario, Caja Insular de Ahorros de Canarias, 1991.

CABRERA ACOSTA, Miguel Ángel: "El resurgimiento del movimiento obrero canario y la repercusión de las huelgas de Asturias", en Rubén VEGA GARCÍA (coord.): El camino que marcaba Asturias. Las huelgas de 1962 en España y su repercusión internacional, Gijón, Ediciones Trea, Fundación Juan Muñiz Zapico, 2002, pp. 221-236.

CABRERA ACOSTA, Miguel Ángel; LÓPEZ TRUJILLO, Zebensui: “Antonio Cubillo: de la oposición al franquismo al nacionalismo africanista canario", en Xosé Manuel NÚÑEZ SEIXAS; Fernado MOLINA APARICIO (eds.): Heterodoxos de la Patria: biografias de nacionalistas atípicos de la España del siglo XX, Granada, Comares, 2011, pp. 221-241.

CALZADA FIOL, Alfonso: La verdad sobre "el Corredera", Las Palmas de Gran Canaria, Inforcasa, 1989.

CUBILlO FERREIRA, Antonio: Trópico gris. Semimemorias-2, Santa Cruz de Tenerife, CCPC, 2005.

DÍAZ BENÍTEZ, Juan José: Anglofilia y Autarquía en Canarias durante la Segunda Guerra Mundial, Santa Cruz de Tenerife, Idea, 2008.

ERICE, Francisco: "La política sindical del PCE en los orígenes de las Comisiones Obreras: las confusiones en torno a la OSO", en Manuel BUENO, Carmen GARCÍA y José HINOJOSA (coords.): Historia del PCE. I Congreso, 1920-1977, Madrid, Fundación de Investigaciones Marxistas, vol. II, 2007, pp. 107-120.

FERNÁNDEZ SOLDEVILLA, Gaizka, LÓPEZ ROMO, Raúl: Sangre, votos, manifestaciones: ETA y el nacionalismo vasco radical (1958-2011), Madrid, Tecnos, 2012.

GARCÍA LÁZARO, Néstor: Las "escrituras criminales" en el contexto de la lucha por las libertades: teoría y práctica en Canarias entre 1959 y 1982, Las Palmas de Gran Canaria, Universidad de Las Palmas de Gran Canaria, Tesis Doctoral inédita, 2013.

107 MCCARTHY, John D., SMITH, Jackie y ZALD, Mayer N.: "El acceso a la agenda pública y a la agenda del gobierno..., p. 441. 
GARCÍA LÁZARO, Néstor: "Escrituras contestarias en contextos dictatoriales. Las Palmas durante el tardofranquismo (1959-1975)", Hispania. Revista española de Historia, (en prensa).

GARÍ HAYEK, Domingo: Historia del Movimiento Canarias Libre: 1960-1962, Las Palmas de Gran Canaria, Benchomo, 1990.

GUERRA PALMERO, Ricardo A.: Sobrevivir en Canarias (1939-1959). Racionamiento, miseria y estraperlo, Santa Cruz de Tenerife, Idea, 2006.

LÓPEZ TRUJILLO, Zebensui: Imaginar la nación canaria: el papel de Antonio Cubillo en el resurgimiento de los movimientos obrero y nacionalista (1956-1978). Trabajo de investigación inédito. Diplomatura en Estudios Avanzados y Suficiencia Investigadora (DEA). Departamento de Historia. Universidad de La Laguna, 2010.

LÓPEZ TRUJILLO, Zebensui: "Historiografía y nacionalismo en Canarias: una primera aproximación", en Roberto GONZÁLEZ (coord.): Actas de las III Jornadas Prebendado Pacheco de Investigación Histórica, Santa Cruz de Tenerife, Ayto. de Tegueste, 2011, pp. 355-374.

MILLARES CANTERO, Agustín: "En busca de la iglesia cubana", en Arturo CANTERO SARMIENTO: Las Palmas 1950: vida, hechos y milagros de la famosa "Iglesia cubana", Las Palmas de Gran Canaria, Ediciones del Cabildo Insular de Gran Canaria, 1993, pp. 7-24.

MILLARES CANTERO, Agustín, DOMÍNGUEZ PRATS, Pilar: "La cuestión nacional entre los comunistas grancanarios (1959-1971)" en Manuel BUENO, Carmen GARCÍA y José HINOJOSA (coords.): Historia del PCE. I Congreso, 1920-1977, Madrid, Fundación de Investigaciones Marxistas, 2007, vol. II, pp. 153-165.

MILLARES CANTERO, Sergio: Fernando Sagaseta, la vida de un luchar irremediable, Las Palmas de Gran Canaria, Centro de la Cultura Popular Canaria, 1994.

MOLINERO, Carme: "Una gran apuesta: la oposición política a través de la movilización social”, en Manuel Bueno Lluch, Sergio Gálvez Biesca (eds.): Nosotros los comunistas. Memoria, identidad e historia social, Fundación de Investigaciones Marxistas / Atrapasueños, Sevilla, 2009, pp. 255-283.

NÚÑEZ SEIXAS, Xosé M.: "Nuevos y viejos nacionalistas: la cuestión territorial en el tardofranquismo, 1959-1975”, Ayer, 68 (2007), pp. 59-87.

QUINTANA, Francisco: “Conflictos laborales y oposición sindical en Las Palmas, 19611973” en Javier TUSELL, Alicia ALTED, Abdón MATEOS (Coords.): La oposición al régimen de Franco. Estado de la cuestión y metodología de la investigación. Actas del Congreso Internacional que, organizado por el Departamento de Historia Contemporánea de la UNED, tuvo lugar en Madrid, del 19 al 22 de octubre de 1988 Tomo I, volumen 2. Madrid, Universidad Nacional a Distancia, 1990, pp. 81-100.

SUÁREZ CABRERA, Carlos: Mañana será mejor, Las Palmas de Gran Canaria, Anroart Ediciones, 2006. 